\title{
Quebra-cabeça sonoro: um jogo chamado criação musical
}

\author{
Sound's Puzzle: a game called musical creation
}

Sandra Mara da Cunha* cunhasandramarada@gmail.com 


\section{Resumo}

Partindo da exploração dos sons produzidos pelo piano, crianças iniciantes no aprendizado desse instrumento têm material para se expressar musicalmente. Como em um quebra-cabeça em que as peças vão sendo acopladas umas às outras para formar uma imagem, temas inventados e organizados por elas dão forma a composições musicais em um jogo no qual elas são as protagonistas. Suas ideias, intenções e escolhas são acolhidas, incentivadas e orientadas e levam à aquisição da linguagem musical e pianística. Ao utilizar como dispositivo metodológico o estudo de caso, este artigo tem como objetivo refletir sobre a participação das crianças nos processos criativos, com base nos campos da educação musical e dos estudos da infância. Em um contexto educativo marcado pela integração de linguagens artísticas e por uma abordagem pedagógica na qual a construção de conhecimento acontece no compartilhamento de saberes entre professores-artistas e crianças, as invenções delas ganham vida e contribuem para a visibilização de seus modos de fazer música.

Palavras-chave:Educação musical; Estudos da infância; Processos criativos, Participação infantil; Iniciação ao piano.

\section{Abstract}

By exploring sounds produced by the piano, young beginners learning the instrument have material to express themselves musically. As in a puzzle where we put the pieces together to form an image, invented and organized by topics, children can form musical compositions in a game in which they are the protagonists. Their ideas, intentions, and choices are accepted, encouraged and oriented and lead to the acquisition of pianistic and musical language. Using a case study as methodological device, this article aims to reflect on the participation of children in creative processes, based on the fields of Music Education and Childhood Studies. In an educational context marked by artistic language integration, through an educational approach where construction of knowledge happens by sharing of expertise between teacher-artists and children, students' inventions come to life and contribute toward the understanding of their music-making processes.

Keywords: Music education; Childhood studies; Creative process; Children's participation; Piano initiation. 
"Não seja em princípio muito meticuloso. Toca, atua, dança. Todos os processos no início são difíceis, desajeitados e incomuns."

Chefa Alonso

\section{Notas iniciais}

Práticas criativas na aprendizagem da música têm sido objeto de estudo no campo da educação musical, tanto do ponto de vista teórico como prático, principalmente a partir da segunda metade do século XX, com as abordagens criativas propostas pela chamada "segunda geração" de educadores musicais. Esses educadores levaram para a sala de aula suas experiências como compositores e propuseram que o som fosse o material básico para se fazer música. Uma das importâncias dessas abordagens reside no caráter de abertura e acolhimento para crianças e jovens aprendizes, que encontram espaço para desenvolverem suas ideias, experiências e interesses musicais dentro do corpo das propostas pedagógicas.

A possibilidade de experimentar materiais produtores de sons, numa ampliação da voz e dos instrumentos musicais convencionais e com eles fazer música desde as primeiras aulas, seja improvisando ou compondo, é característica dessas abordagens. Segundo Fonterrada (2015):

Os procedimentos em geral utilizados nas práticas criativas e na Improvisação Livre incentivam a escuta, a tomada de decisões, o desenvolvimento da autonomia, o reconhecimento de si e do outro, por meio de propostas que priorizam a invenção musical e o improviso; além disso, seu caráter prático e musical atrai os participantes que, em geral, se atemorizam quando se defrontam com o caráter tecnicista encontrado em muitas aulas de música. (FONTERRADA, 2015, p. 19, grifos meus).

Nessas abordagens em que os interesses investigativos sobre os sons e sobre a possibilidade de se fazer música com eles, organizando-os em sistemas musicais outros que não os hegemônicos que caracterizam o ensino tradicional - focado no desenvolvimento de habilidades técnicas e voltado para a formação profissional adulta -, a atuação dos professores sofre mudanças. As relações marcadas pela parceria, pelo compartilhamento de saberes e pela conscientização de conceitos musicais a partir do fazer musical presente em aulas e cursos baseados nas propostas dessas abordagens pedem revisões dos papéis profissionais dos docentes. Koellreutter (apud BRITO, 2001), por exemplo, pensava que:

Não é preciso ensinar nada que o aluno possa resolver sozinho. É preciso aproveitar o tempo para fazer música, improvisar, experimentar, discutir e debater. O mais importante é - sempre - o debate e, nesse sentido, os problemas que surgem no decorrer do trabalho interessam mais do que as soluções. (KOELREUTTER apud BRITO, 2001, p. 32). 
Ao tratar da iniciação de crianças no estudo do piano, o presente artigo tem como objetivo principal pensar a participação delas nos processos criativos na aprendizagem musical, a partir do modo como o ensino desse instrumento vêm sendo desenvolvido e pensado por essa autora em uma escola de iniciação artística na qual a música é uma das linguagens que compõem a formação das crianças, de modo integrado às Artes Visuais, à Dança e ao Teatro.

Nessa escola voltada para crianças, o ensino do instrumento musical se dá de modo inicial e não profissionalizante e, pelas suas características constitutivas enquanto espaço artístico e educativo, faz-se importante enfatizar que a cultura da participação se encontra enraizada não apenas nas práticas pedagógicas com as crianças, mas também nas relações entre professores e destes com a escola e seu corpo diretivo. Com isso, temos um ambiente que é terreno fértil e acolhedor para as experimentações e escolhas das crianças, que resultam em criações em todas as áreas artísticas, sendo que a aprendizagem dos instrumentos musicais se encontra mergulhada nesse tempo-espaço criador de possibilidades expressivas para a infância. Falo então de uma aprendizagem no instrumento e na música em um contexto singular, uma aprendizagem que é situada e plena de significados para as crianças.

Tendo como ponto de partida para a iniciação ao estudo do piano a exploração sonora do instrumento, as crianças improvisam nas aulas e, a partir dessas experimentações de possibilidades de tocar e de fazer música que são facilitadas por um conhecimento artístico já experimentado e desenvolvido em outras aulas na escola, surgem sonoridades, temas e ideias musicais que capturam o interesse criativo das crianças. Essas ideias, aos poucos, são organizadas como em um jogo de quebra-cabeça no qual as peças vão sendo acopladas para formar uma imagem e dão forma a composições que revelam pensamentos, concepções artísticas, visões de mundo e de vida das crianças. Essas músicas, pensadas, moldadas e tocadas pelas crianças, tornam visível e audível o conhecimento musical, artístico e humano construído também por elas mesmas nessa escola.

Ao trabalhar com improvisações livres e com composições das crianças, estabelece-se nas aulas as conexões possíveis com músicas de outros compositores que elas começam a tocar e a conhecer e, desse modo, avançam no estudo e no domínio técnico e estético do instrumento. Nesse processo, o conhecimento acumulado no ensino do piano ao longo do tempo, com as questões da linguagem musical a ele aplicadas, dialoga com as improvisações e composições das crianças, e todo esse aprendizado se alimenta e se retroalimenta em várias direções pelos significados que as crianças atribuem a esse estudo, tornando-o vivo e pulsante.

As crianças e seus modos de tocar e de fazer música nos informam sobre suas competências também no campo da música e da arte, e revelam que sua participação nos processos de aprendizagem é vital para que elas possam ser também autoras da construção do seu conhecimento musical por meio do instrumento que começam a estudar.

Ao abordar o tema da participação infantil pensada a partir do estudo do instrumento na Escola Municipal de Iniciação Artística de São Paulo (EMIA), a intenção tam- 
bém é a de que nós, professores de crianças, nos mantenhamos abertos e atentos na nossa prática pedagógica, à condução da iniciação ao estudo do instrumento e da música, dado que as crianças têm mostrado que sua aprendizagem artística precisa ser plena de sentidos para elas, e não apenas para nós, adultos.

\section{A EMIA: contexto formativo, criativo e participativo}

A Escola Municipal de Iniciação Artística de São Paulo (EMIA) é uma escola de iniciação à arte que pertence à Secretaria Municipal de Cultura e funciona desde 1980 em três casas que ficam dentro do Parque Lina e Paulo Raia, no bairro Jabaquara, situado na zona sul da cidade. Seus princípios artístico-pedagógicos podem ser assim expressos: iniciação à arte por meio de processos criativos, marcados pela participação das crianças nas linguagens das artes visuais, da dança, da música e do teatro, e orientados por professores que são artistas, chamados na escola de artistas-professores e aqui, nesse texto, de professores-artistas.

O acesso à EMIA ${ }^{1}$ é feito mediante sorteio, e nela estudam crianças de cinco a treze anos de idade. O curso regular da escola é obrigatório para todas e contempla, nos quatro primeiros anos, duplas de professores de duas linguagens diferentes, primeiramente em aulas de duas horas de duração, nos chamados grupos Cinco Anos e Seis Anos, e depois em aulas de três horas semanais, nos grupos Sete Anos e Oito Anos. No quinto e sexto anos de estudos na escola, as crianças têm a oportunidade de fazer parte do "Quarteto" em aulas semanais de três horas e meia de duração com quatro professores, cada um de uma área artística diferente, que trabalham sob o princípio da integração de linguagens. Nos dois últimos anos, as crianças escolhem uma das linguagens artísticas para se dedicarem em aulas de três horas com um ou dois professores da mesma área.

Em paralelo a esse curso regular, elas têm a possibilidade de fazer cursos optativos em todas as linguagens, além de oficinas e de cursar um dos grupos permanentes, como os corais e a orquestra infantojuvenil da escola. $O$ estudo do instrumento encontra-se na categoria dos cursos optativos e é oferecido para crianças a partir dos sete anos de idade. A procura pelo estudo dos instrumentos é grande e não há garantia de vagas para todos os interessados, pois estas dependem da disponibilidade de dias e horários dos professores, que também atuam nos grupos de integração de linguagens, nas chamadas "duplas" ou "quartetos" no jargão da escola. Devido a esse número de vagas menor do que a quantidade de interessados, estabeleceu-se que as crianças mais velhas e que têm mais tempo de EMIA têm prioridade nas chamadas para o estudo dos instrumentos.

A iniciação das crianças no mundo da arte e seus fazeres e saberes na EMIA se alimenta dos princípios da aprendizagem artística por meio de processos criativos, da integração de linguagens e da participação infantil. Nesses processos que acontecem nas aulas das "duplas" e "quartetos", as crianças se envolvem nos projetos lançados por seus professores a cada início de ano ou semestre, e suas ideias são acolhidas, estimu-

1 EMIA - Escola Municipal de Iniciação Artística de São Paulo. Para maiores informações, acesse: http://www.prefeitura.sp.gov.br/cidade/secretarias/cultura/dec/formacao/iniciacao_artistica/index.php?p=7372>; http://emiasp.blogspot.com.br/>; https://www.facebook.com/ emia.escolaemia/>; https://www.youtube.com/watch?v=gH8UcdAANLo>; <https://www.youtube.com/watch?v=L2Z6wDjVC1k>. 
ladas, orientadas e dão vida aos seus interesses de pesquisa, de ação e de atuação em todas as linguagens.

As aulas das "duplas" e "quartetos" buscam a integração de linguagens, o desmanche dos limites entre áreas artísticas, e procuram trabalhar entre uma e outra, em conexão com as crianças pequenas, que desconhecem essas fronteiras e atuam nesses entre espaços expressivos. Schafer (1991) já nos chamava a atenção para essa expressão infantil que ele afirmava ser "um fluido caleidoscópico e sinestésico" (SCHAFER, 1991, p. 290). O compositor-educador considera que "essa fragmentação do sensorium total seja a mais traumática experiência na vida da criança pequena" (SCHAFER, op. cit., p. 290).

A EMIA pode ser pensada, portanto, como um espaço-tempo educativo acolhedor para a infância e para o modo de ser das crianças que ali chegam para fazer parte dela, uma escola na qual as crianças podem continuar se expressando de modo fluido no trânsito entre linguagens. As linguagens artísticas são, também, linguagens infantis (CUNHA, 2014b). Muitas vezes, nas aulas, principalmente nos "Quartetos", nós, professores da escola, observamos as crianças e nos regozijamos ao assisti-las sem conseguirmos definir se o que fazem é música, dança, teatro ou artes visuais. Até para as crianças algumas vezes fica difícil estabelecer as fronteiras entre uma e outra linguagem nas suas ações artísticas e nomear o que fazem como pertencente a apenas uma delas.

A escola não atribui notas aos seus alunos, todos "passam de ano". O currículo é aberto e se constrói no compartilhamento e na construção de saberes e de saber-fazer entre adultos e crianças. Os professores trabalham em sintonia com o envolvimento das crianças nos projetos, e as mudanças de rota, quando acontecem, não são negadas, são, antes, parte desse processo de ensino e aprendizagem.

Ao final de cada semestre, os professores se debruçam sobre seus registros e contam sobre o desenvolvimento dos projetos, com seus acontecimentos mais marcantes, nas "Narrativas Poéticas da EMIA" (CUNHA, 2014a, 2016). Faz parte das "Narrativas" explicitar o currículo que emerge dos trabalhos, do que de fato foi construído com as crianças em cada linguagem ou na integração entre elas, e podemos falar que na EMIA o currículo se dá de modo posposto, pois ele é plenamente conhecido ao final de cada semestre. As "Narrativas" têm o importante objetivo de tornar visível o conhecimento artístico construído com as crianças.

O papel dos professores ganha novos significados na EMIA. De ensinadores, passamos a ser parceiros das descobertas das crianças. Tentamos proporcionar a elas a possibilidade de experimentarem materiais variados e modos de lidar com eles, de como trabalhá-los, buscando a melhor maneira de dar vida não apenas ao que foi planejado por nós, adultos, para elas, mas também a encontrar os meios de contribuir para que as crianças possam, elas mesmas, esculpir e tornar vivas suas ideias e interesses nas diferentes linguagens ou no fluxo entre todas elas.

$\mathrm{Na}$ EMIA, falamos de encontros e de integrações: entre linguagens artísticas, entre adultos e crianças, entre crianças e entre o fazer artístico e o pedagógico. Nesse espaço de criação e de vida compartilhada, professores-artistas e crianças se encontram, e um interesse em comum possibilita, permeia e potencializa esse encontro: a arte e seus fazeres e saberes; queremos fazer e criar arte, juntos. O conhecimento artístico e 
o domínio técnico dos procedimentos de feitura, do lado dos professores, e a imaginação fértil e a criatividade latente das crianças se dão as mãos e o resultado explode em cores, corpos dançantes, ocupação de tempos e espaços, sons e músicas.

Os caminhos de descoberta e aquisição de conhecimento artístico pelas crianças são acolhidos, e o que fazemos é orientar, levar referências, fazer relações e conexões, dando a elas opções e fazendo com que se sintam também responsáveis, porque cada caminho leva a um acontecimento e é importante que tomem consciência de suas escolhas e a relação delas com os resultados a serem alcançados. Para as crianças, qual é o resultado que se mostra como o mais apropriado para expressar o que sentem, pensam, querem fazer e mostrar? Rocha (2017), ao narrar memórias de ex-alunos da escola, nos conta que:

Certamente ninguém pode ensinar ninguém a se apaixonar - os signos vibram em cada um de nossos alunos de modo singular e intransferivel e cabe a eles eleger os que lhes são próprios e lhes dizem respeito. Mas, principalmente enquanto vivem a infância das suas afinidades e eleições, podemos procurar facilitar e incitar os encontros e as experiências nesse sentido e acolher as tendências que ensaiam se manifestar. (ROCHA, op. cit., p. 147)

[...]Em uma linguagem e outra, vivendo os encontros entre uma linguagem e outra, importa que se sintam percebidos e incluídos na roda, nas atividades e nas criações, encontrando lugar para seus modos singulares de expressão. (ROCHA, op. cit., p. 148).

Nesse contexto de trocas de saberes entre adultos e crianças que leva à construção de conhecimento em Arte, os trabalhos das crianças são valorizados, estejam eles em processo de feitura ou finalizados. Esses trabalhos são mostrados em várias oportunidades, desde os compartilhamentos entre grupos de um mesmo dia e horário às mostras que marcam o calendário de eventos da escola, como a Viradinha Musical, a Exposição de Formandos de Artes Visuais, o Criança Criando Dança, a Ocupação de Teatro, a Super Semana ou as apresentações do final de ano, chamadas carinhosamente por todos de "João Caetano", em função de ser esse o teatro municipal que mais tem acolhido essas apresentações.

\section{A participação das crianças na EMIA}

A participação infantil é um tema que vem sendo estudado pelo campo multidisciplinar dos estudos da infância (BARBOSA; COLL DELGADO; TOMÁS, 2016) e ganhou relevância a partir da aprovação da Convenção dos Direitos da Criança pela ONU, em 1989. A participação, ao lado da provisão e da proteção, é direito fundamental das crianças, e ela tem sido objeto de pesquisas nos níveis macro e microssocial, das políticas públicas ao ambiente familiar e escolar. Esse último, o das relações que se estabelecem 
entre adultos e crianças nos ambientes educativos, é o foco que me interessa particularmente nas reflexões lançadas neste texto, tendo a EMIA como seu lócus de estudo para pensar a aprendizagem das crianças na escola em geral, e no piano em particular.

O termo participação é um conceito polissêmico e, nas reflexões aqui contidas, pode ser compreendido ou, melhor dizendo, ele é aqui conjugado enquanto verbo. Participar significa ter uma voz que fala e que é ouvida e, mais do que isso, que é considerada nas tomadas de decisão. Pode ser coletiva ou individual e diz respeito tanto ao processo como ao resultado alcançado. Além disso, convém nos atentarmos para o fato de que ela não acontece no vazio, mas se dá (ou não) nas relações sociais.

Deixo claro, entretanto, que ter voz, do modo como a participação acontece na EMIA, escola de arte para crianças e com crianças, envolve falar por meio de múltiplas vozes, pois as crianças falam com seus corpos dançantes, por intermédio das cores que escolhem para suas pinturas, falam através das personagens que interpretam e também por meio das músicas que tocam, sejam elas de sua autoria ou de outros compositores. Para pensar sobre essa questão de modo ampliado, trago um trecho da reflexão de uma professora sobre a participação das crianças nas suas aulas²:

Ao refletir sobre o meu fazer artístico-pedagógico com as crianças no ateliê de artes visuais, e pensando sobre o como se dá a participação delas nesse processo, percebo que muitas vezes a voz participativa não necessariamente ecoa, mas silenciosamente transforma. (Adriana Amaral, professora-artista de artes visuais. Optativo de artes visuais, grifos meus). ${ }^{3}$

No contexto da EMIA, a participação das crianças acontece no envolvimento direto delas com o desenvolvimento e a consecução dos seus trabalhos, no seu papel no desenrolar das aulas, nas escolhas que elas fazem tanto em relação ao seu percurso na escola como na construção do seu conhecimento artístico. As crianças escolhem os cursos optativos que querem fazer, determinando assim um currículo que tem um componente de singularidade, porque, enquanto algumas cursam apenas o curso regular e obrigatório, outras fazem cursos optativos em mais de uma área e outras, ainda, também fazem as oficinas, tudo a depender do interesse delas e das possibilidades de acolhimento desses interesses por suas famílias. Nesse ponto, é importante reiterar que a escola é pública e que crianças de diferentes classes sociais, raças e culturas convivem nesse espaço educativo, o que determina as frequências e permanências, entre outros aspectos.

Do ponto de vista da cotidianidade das aulas, na convivência com seus professores e colegas, as crianças têm espaço para emitir suas opiniões. Elas são estimuladas a defender suas ideias e pontos de vista, fazem escolhas relativas a tempos, espaços, optam por materiais e modos de organizá-los, em conjunto ou individualmente. Elas 
também tomam parte nas decisões sobre como apresentar seus trabalhos nas mostras que acontecem o tempo todo na escola; decidem até mesmo que não desejam apresentar seus trabalhos.

Para ajudar a pensar sobre a questão da participação infantil na EMIA, recorro inicialmente a Hart (1992), que propôs a chamada "escada da participação", construída a partir do modelo de Sherry Arnstein (1969) sobre a participação cidadã. Cada um dos oito degraus da escada de Hart aborda um diferente nível participativo. Os degraus mais baixos tratam da não participação, que são a manipulação, o Tokenismo (participação simbólica) e a consulta. Os outros cinco degraus sequentes abordam diferentes formas de participação infantil na sociedade desde o quarto nível, em que as crianças são apenas informadas sobre a decisão adulta, ao oitavo degrau, em que elas iniciam e conduzem os processos participativos e informam aos adultos suas decisões.

Considero importante frisar que o dispositivo de Hart ajuda a pensar sobre a participação infantil, mas não creio que deva ser usado para classificar ações pedagógicas e atitudes dos professores na relação com as crianças, tanto na EMIA como em outros contextos educativos. Não é para julgar, mas para trazer esclarecimentos sobre as diferenças existentes entre as formas não participativas e as participativas e para nos fazer repensar nossas atitudes educativas e relacionais com as crianças.

O modo como nós professores conduzimos nossa atuação com as crianças revela como as concebemos e o que pensamos sobre elas. A concepção de infância que fundamenta meu trabalho, tanto empírico como teórico, é a que é expressa pelos Estudos da Infância, particularmente pela Sociologia da Infância, que advoga que as crianças são seres competentes que possuem saberes e experiências, são sujeitos de direitos que podem falar por elas mesmas para expressar seus pontos de vista.

A Sociologia da Infância tem como princípio estruturante o paradigma da competência infantil, ou, como afirma Sarmento (2009, p. 22, grifos meus), todas as crianças são competentes no que fazem, considerando a sua experiência e as suas oportunidades de vida, sendo que as suas áreas de competência são distintas das áreas de competência adulta". Ter em mente que a competência infantil é distinta da competência adulta nos ajuda, enquanto professores na atuação com crianças, a não exigir delas o que ainda não são capazes de fazer de um ponto de vista adulto e profissional, como no caso de esperar delas precisão para tocar e cantar, mas a compreender que elas estão em processo de aquisição de conhecimento e de exercício de habilidades artísticas nessa escola.

Ainda de acordo com Sarmento (op. cit.), "é da ordem da diferença e não da grandeza, incompletude e imperfeição, que a Sociologia da Infância trata quando estabelece a distinção das crianças face aos adultos" (Ibidem, p. 22). Em outro texto de sua autoria, o autor discorre um pouco mais sobre essa ideia da diferença das crianças em relação aos adultos, pensada no sentido das potências expressivas das crianças, que, segundo o autor:

[...] a infância deve a sua diferença não à ausência de características (presumidamente) próprias do ser humano adulto, mas à presença de outras características 
distintivas que permitem que, para além de todas as distinções operadas pelo facto de pertencerem a diferentes classes sociais, ao gênero masculino ou feminino, seja qual for o espaço geográfico onde residem, à cultura de origem e etnia, todas as crianças do mundo tenham algo em comum.

Assim sendo, a infância não é a idade da não-fala: todas as crianças, desde bebês, têm múltiplas linguagens (gestuais, corporais, plásticas e verbais) por que se expressam. A infância não é a idade da não-razão: para além da racionalidade técnico-instrumental, hegemônica na sociedade industrial, outras racionalidades se constroem, designadamente nas interacções de crianças, com a incorporação de afectos, da fantasia e da vinculação ao real. (SARMENTO, 2007, p. 35 e 36, grifos meus).

Voltando à questão da participação infantil, para Lansdown (2010, p. 20), o engajamento das crianças nas situações em que elas se encontram envolvidas pode ser avaliado pelo nível desse envolvimento. Como exemplo, propõe que a participação infantil possa ser amplamente classificada em três níveis:

- Participação Consultiva - É proposta, conduzida e mantida pelos adultos e não envolve o compartilhamento ou a transferência da tomada de decisão para as crianças. É um modo de habilitá-las para expressar seus pontos de vista. Encontro esse tipo de participação nas rodas de conversa, que acontecem bastante na EMIA: as crianças falam suas opiniões a partir de um tema ou questão levantada pelos professores, principalmente, mas também conversam sobre assuntos levantados pelas próprias crianças. Suas falas podem ou não levar a resultados dos quais elas de fato tomaram parte nos processos de decisões.

- Participação Colaborativa - Caracteriza-se por ser um estágio mais avançado na parceria entre adultos e crianças e envolve a oportunidade para um engajamento ativo delas em qualquer estágio de decisão, iniciativa, projeto ou serviço. A colaboração participativa proporciona às crianças oportunidades para compartilhar decisões tomadas com os adultos e para que elas influenciem tanto os processos como as tomadas de decisão junto aos adultos.

- Participação conduzida por crianças - Acontece quando as crianças encontram espaço e oportunidade para identificar temas concernentes aos seus interesses, em que podem iniciar atividades e advogar em seu próprio nome. Elas podem iniciar ações tanto individualmente como em grupo, e o papel dos adultos é agir como facilitadores, oferecendo-lhes informações, conselhos e suporte para conseguirem atingir seus objetivos. Esse tipo de participação acontece em projetos sociais ou comunitários como os que são estudados por Cussiánovich (2002) na América Latina, com crianças maiores e jovens, por exemplo.

Olhando mais detidamente para as relações dos professores-artistas com as crianças na EMIA, enquanto pesquisadora da infância e da educação musical e também como membro do corpo docente dessa escola, a partir dos referenciais aqui mencionados, dentre outros, posso afirmar que a EMIA é um espaço educativo que promove a participação infantil. Essa participação pode ser pensada a partir do que nos propõe Lansdown com a participação colaborativa. 
Os processos de ensino-aprendizagem se iniciam com o planejamento dos projetos anuais pelos professores, nos grupos ou individualmente, e se desenvolvem nas aulas, muito a partir do que as crianças trazem com elas quando chegam à escola. Esses projetos preveem, para a sua consecução, a contribuição das crianças para o seu desenvolvimento: são eminentemente colaborativos, e os professores se abrem e se propõem a investigar junto com as crianças algum tema ou assunto que é prenhe de possibilidades artísticas, de integrações, de caminhos.

Do ponto de vista adulto, no trabalho com crianças, e não apenas para crianças, considero importante pautar as ações pedagógicas pela observação atenta das crianças e da busca dos significados que elas atribuem ao que fazem quando estão sob minha orientação. Dada a diversidade de crianças que estudam nessa escola pública, faz-se fundamental respeitar suas condições de vida, relativas às suas pertenças de classe, gênero, raça e cultura, de modo a compreender seus pontos de vista, igualmente válidos no desenvolvimento dos projetos dos grupos dos quais fiz e faço parte atualmente, e também nas aulas de piano.

Nesse caminho de pensar as crianças na EMIA, com o foco na participação infantil, a intenção tem sido a de conferir maior visibilidade a elas em sua expressão artística, reveladora de pensamentos, modos de ser e de fazer, diferentes dos adultos em termos de qualidade, assim como afirmou Sarmento (2007), e dos significados atribuídos por elas, e não apenas por mim. Meu intuito é também o de compreender e ressaltar seu protagonismo nos processos de experimentação, investigação e de atuação artística, respeitando, ao mesmo tempo, seus níveis de vulnerabilidade face às suas idades, o que requer viver nessa linha tênue existente entre a proteção e a participação infantil, direitos que devem ser igualmente respeitados quando trabalhamos com crianças.

Sendo assim, qual seria o lugar da participação das crianças no estudo de um instrumento, especificamente falando sobre esse contexto educativo? Estaria na escolha das músicas que querem tocar? Estaria no acolhimento e no incentivo às suas músicas preferidas que elas aprendem a tocar sozinhas em vídeos e tutoriais que buscam na internet ou que trocam com seus amigos e me pedem ajuda para melhor entendê-las e tocá-las de modo mais adequado? Estaria nas aberturas para suas improvisações e criações e para as escolhas que elas fazem enquanto autoras de suas próprias músicas? Em qualquer que seja a opção aqui questionada, as concepções estéticas das crianças, muitas vezes distintas das minhas, caracterizam um desafio a ser constantemente enfrentado. Como acolher suas opções estéticas? Como orientar sem desconsiderar outras visões estéticas e de mundo?

Nesse caminho de me fazer professora na relação estreita com as crianças e seus modos de ser e de pensar, as relações são marcadas pela escuta delas e pela consideração de seus pontos de vista, com negociações que acontecem o tempo todo. Mas uma coisa é comum a todas as crianças que chegaram e que chegam até mim: o interesse e a vontade de tocar piano. Fornecer-lhes condições para que toquem e se expressem ao piano, fazendo uso dos procedimentos necessários para que essa expressão possa seguir para além do que aprendem na EMIA, é também um objetivo a ser alcançado. Algumas se dão por satisfeitas e seguem tocando com maior ou menor intensidade de- 
pois de se formarem na escola. Outras querem seguir estudando piano e são preparadas para os testes nas escolas públicas que oferecem continuidade para suas formações musicais. Dialogar com esses interesses distintos é ponto constituinte do meu trabalho com as crianças no estudo do piano.

Desse modo, compreendo que a participação das crianças na sua iniciação ao estudo do piano na EMIA encontra-se na possibilidade de que, para além das escolhas de repertório que elas fazem, e dos caminhos que pretendem seguir ao finalizar seus percursos na escola, elas também encontrem espaço para experimentar e inventar suas próprias músicas. Que tenham espaço e que sejam acolhidas ao lidar com elementos da linguagem musical que são experimentados, escolhidos e que ganham formas, com decisões tomadas por elas ou negociadas comigo, cujos resultados expressam suas opções e possibilidades de consecução artísticas e estéticas.

A materialização de ideias e de um conhecimento musical posto em ação quando improvisam e compõem suas músicas não significa, de modo algum, escolhas desqualificadas, visto que nascem e ganham vida na parceria com seus professores na EMIA, que são também artistas conhecedores das linguagens, de seus elementos constitutivos e dos seus processos de feitura.

A arte e suas múltiplas linguagens, em sua dimensão criadora, implica a invenção autoral, porque quem a pratica é também capaz de inventar cenas, danças, músicas, pinturas, modelagens porque, como afirmam Lino e Richter (2016, p. 2),

[...] que se a possibilidade de aprender as dimensões da linguagem seja resultado de processos de aprendizagem, não significa que tudo que as crianças e adultos dizem e escrevem, que desenhem e cantem, que leem e dancem, tenha thes sido ensinado. Eles podem também inventar, criar, improvisar, e o melhor modo pelo qual os maiores podem ensinar aos pequenos é aquele que permite a eles aprenderem como se faz para inventá-lo.

Colocar o foco da ação educativa no encantamento das crianças com as suas descobertas sonoras, com o desafio que se impõe quando elas querem tocar suas músicas ou, posto de outro modo, na iniciação ao estudo do instrumento por meio da experimentação livre ou direcionada com base na conscientização acerca dos seus elementos constitutivos, é uma questão que deve ser seriamente pensada no ensino da música com crianças. De outro modo, corremos o risco de desconsiderar os interesses delas e, mais ainda, os contextos de vida de cada criança em particular, e pensaremos que a música tem vida própria, esquecendo-nos de que ela é atividade social, profundamente imbricada nas produções de sentido que lhes conferimos. Com as crianças, não poderia ser diferente.

Crescer em sua própria música e em sua própria ação e produção artística requer, dos professores, a capacidade para burilar o ouvir as crianças, a atitude profunda e respeitosa que vai além de fazermos com elas rodas de conversa nas quais lhes perguntamos o que acham disso ou daquilo, porque muitas vezes isso pode ser apenas consulta (THOMAS, 2007). Porque, se assim o for, o que elas nos dizem não modifica em nada 
nosso modo de conduzir o trabalho. As concepções estéticas adultas também precisam ser repensadas quando o trabalho artístico é feito com crianças nos contextos educativos e artísticos nos quais elas se encontram inseridas.

Nesse ponto, encontro apoio em Olsson (2013), porque a pesquisadora afirma ser necessário questionar o conhecimento estabelecido - aqui, particularmente, a estética adulta - e adotar a emergência do interesse das crianças como princípio de trabalho com elas. A "eventização"4, como um conceito que também pode ser norteador para as aprendizagens artísticas, nos conta de tempos outros, dos tempos da experiência estética e do aqui e agora, porque às crianças interessam mais as impermanências da ação e da produção artística do que as permanências das obras de arte.

Aprender arte é, para as crianças, agir criativamente no mundo, atuando por meio de outras racionalidades e em profunda sintonia com a própria arte, que opera com as razões da sensibilidade, da imaginação e da intuição, nos embates com materialidades várias e suas resistências que convidam os artistas a dominá-las, moldá-las e transformá-las em algo que lhes faça sentido, que lhes traga regozijo e expresse aquilo que as palavras não dão conta de dizer.

Esse é o modo de operar da arte e o modo da infância de aprender a ser e a viver. O modo dos artistas e das crianças de deixarem suas marcas no mundo. Nesse campo em específico, ouvir as vozes das crianças e materializá-las, como resultado de sua participação nos processos de ensino-aprendizagem na EMIA, requer de nós, professores, portanto, o exercício de outras escutas. Na música em particular, estou falando daquilo que nomeio como "dupla escuta": para o fenômeno sonoro e para as crianças fazendo suas músicas (CUNHA, 2014b).

\section{As aulas de piano na EMIA: crianças inventando suas músicas}

Quando as crianças escolhem estudar um instrumento na EMIA, o que acontece quando têm a partir de sete anos de idade e estão na escola há pelo menos um ano, é que chegam ao primeiro encontro com uma compreensão de como funcionam as aulas nesse espaço educativo: suas vozes são ouvidas, suas ideias e seus interesses compõem a tessitura das aprendizagens.

Se isso acontece na condução do trabalho com os grupos de crianças do curso regular, no optativo de música - instrumento -, esse procedimento passou a se constituir como uma abordagem educativa a ser buscada nas minhas aulas de piano na escola, porque acredito que a EMIA, para além de ser uma escola de crianças, é também um espaço no qual os professores se formam, se reformam e se transformam ao entrar em contato uns com os outros e aprendem nas trocas e compartilhamento de saberes.

Nessa proposta de integração de linguagens, aprendi muito com as outras áreas

\footnotetext{
$4 \quad$ "Eventização" ou "eventização do currículo", ideia formulada pela autora a partir do conceito filosófico de "evento" tal como proposto por Deleuze e Guattari (OLSSON, 2012), que pode, de modo sucinto, ser aqui compreendida como uma alternativa a um modo de atuar na educação que concebe o conhecimento como algo estável e permanente, já dado de antemão. A "eventização", por outro lado, seria trabalhar com as crianças observando-as atentamente e, com isso, descobrir o tipo de relação que elas têm, de fato, com o que estão aprendendo, numa ideia de aprendizagem como produção de sentido que é atribuído pelas crianças.
} 
artísticas e com os modos de trabalho com crianças de cada um(a) dos(as) professores(as) parceiros(as) com quem tive e tenho a oportunidade de trabalhar ao longo de todos esses anos. Com elas e eles, aprendi, observando, vendo e ouvindo como conduziam e conduzem seus trabalhos com as crianças, essencialmente pela via da criação artística, pelo respeito e pela escuta atenta e sensível pelo que elas têm a dizer e pelos seus modos de fazer e de ser.

Gosto de alimentar o imaginário das crianças. Acredito que, ao fazer isso também alimento minha imaginação de professora-artista. Aprendo muito com elas. Trabalhar nessa escola me possibilita ver o mundo com olhos de crianças, ouvir o mundo com ouvido de crianças; a EMIA é mesmo casa de crianças (CUNHA, 2016). Sobre o imaginário das crianças, Sarmento (2003) afirma que:

O imaginário infantil é inerente ao processo de formação e desenvolvimento da personalidade e racionalidade de cada criança concreta, mas isso acontece no contexto social e cultural que fornece as condições e as possibilidades desse processo. As condições sociais e culturais são heterogéneas, mas incidem perante uma condição infantil comum: a de uma geração desprovida de condições autónomas de sobrevivência e de crescimento e que está sob o controlo da geração adulta. (SARMENTO, 2003, p. 3).

No piano, especificamente falando, desde a primeira aula tocamos juntos, porque as crianças chegam querendo mesmo é tocar piano. Faço acompanhamentos nas teclas pretas e as convido a explorarem comigo o instrumento. Fazemos passeios por lugares nos quais podemos "falar" alto, e em outros temos que tocar bem suave, para não acordar bebês que dormem. As crianças podem tocar com apenas um dedo, tal como propõe Violeta Gainza (1987) na obra Palitos Chinos, ou podem experimentar tocar com todos os outros dedos ou com toda a mão, fazendo clusters. ${ }^{5}$

As teclas brancas e outras tantas combinações de brancas e pretas resultam em sonoridades que, do ponto de vista de um ensino tradicional, poderiam ser chamadas de "dissonantes", mas, para as crianças, são possibilidades de combinações inusitadas de sons desse novo instrumento que querem descobrir, experimentar e tocar. Nesse e em outros jogos e exercícios exploratórios, vão percebendo que o gesto leva a resultados sonoros e, com as sonoridades produzidas, criam climas perfeitos para serem por elas habitados.

Algumas crianças são mais tímidas, outras se lançam completamente nessas descobertas e são logo fisgadas pelos resultados de suas músicas, assim como me disse Vinicius $^{6}$ (dez anos), conhecedor profundo dos pokémons. Ele, depois de ter tocado a

5 Maria de Lourdes Junqueira Gonçalves, na obra Educação Musical através do Teclado (1986), pensada para o ensino de piano em grupo, propõe começar com a mão fechada com todos os dedos juntos tocando grupos de notas - os clusters - ou, no dizer dela em um curso para divulgação da sua proposta que fiz quando ainda era estudante de graduação, como um "cacho de uvas". Em seguida, em uma posição da mão ainda fechada, o dedo indicador se destaca desse cacho, como se fosse uma pequena uva, e passa a tocar individualmente as teclas (MONTANDON, 1992, p. 121).

6 Maria de Lourdes Junqueira Gonçalves, na obra Educação Musical através do Teclado (1986), pensada para o ensino de piano em grupo, propõe começar com a mão fechada com todos os dedos juntos tocando grupos de notas - os clusters - ou, no dizer dela em um curso para divulgação da sua proposta que fiz quando ainda era estudante de graduação, como um "cacho de uvas". Em seguida, em uma posição da mão ainda fechada, o dedo indicador se destaca desse cacho, como se fosse uma pequena uva, e passa a tocar individualmente as teclas (MONTANDON, 1992, p. 121). 
música que criou a partir de suas improvisações - uma composição de caráter insistente sobre o mesmo grupo de teclas pretas tocadas com os dedos realizando movimentos contrários, nomeada por ele de "música do nada" -, afirmou extasiado: "Emocionante! Ficou legal!".

Nesse caminho da improvisação livre ou mais dirigida que leva às composições, surgem ideias musicais, sonoridades que passam a ser perseguidas porque capturam o interesse estético ou a imaginação das crianças. Elas criam temas que volta e meia retornam às improvisações que fazem quando as acompanho com ostinatos ou quando brincamos de "conversar" tocando piano, ou mesmo quando brincam de tocar em suas casas.

Perguntas e respostas surgem tal como na proposta pedagógica de Orff, ou em outras que fui criando com as crianças, como a história dos dedos das mãos que têm personalidades diferentes: um quer sair do lugar, explorar e conhecer o mundo, enquanto o dedo da outra mão só quer ficar na mesma tecla, no que chamo de "um vai e outro fica", e essas brincadeiras de tocar orientam a criação no instrumento. Larissa (oito anos, 2012) não apenas criou a sua versão para esse jogo, como também chegou com ela escrita em cores, como se vê na Fig. 1:

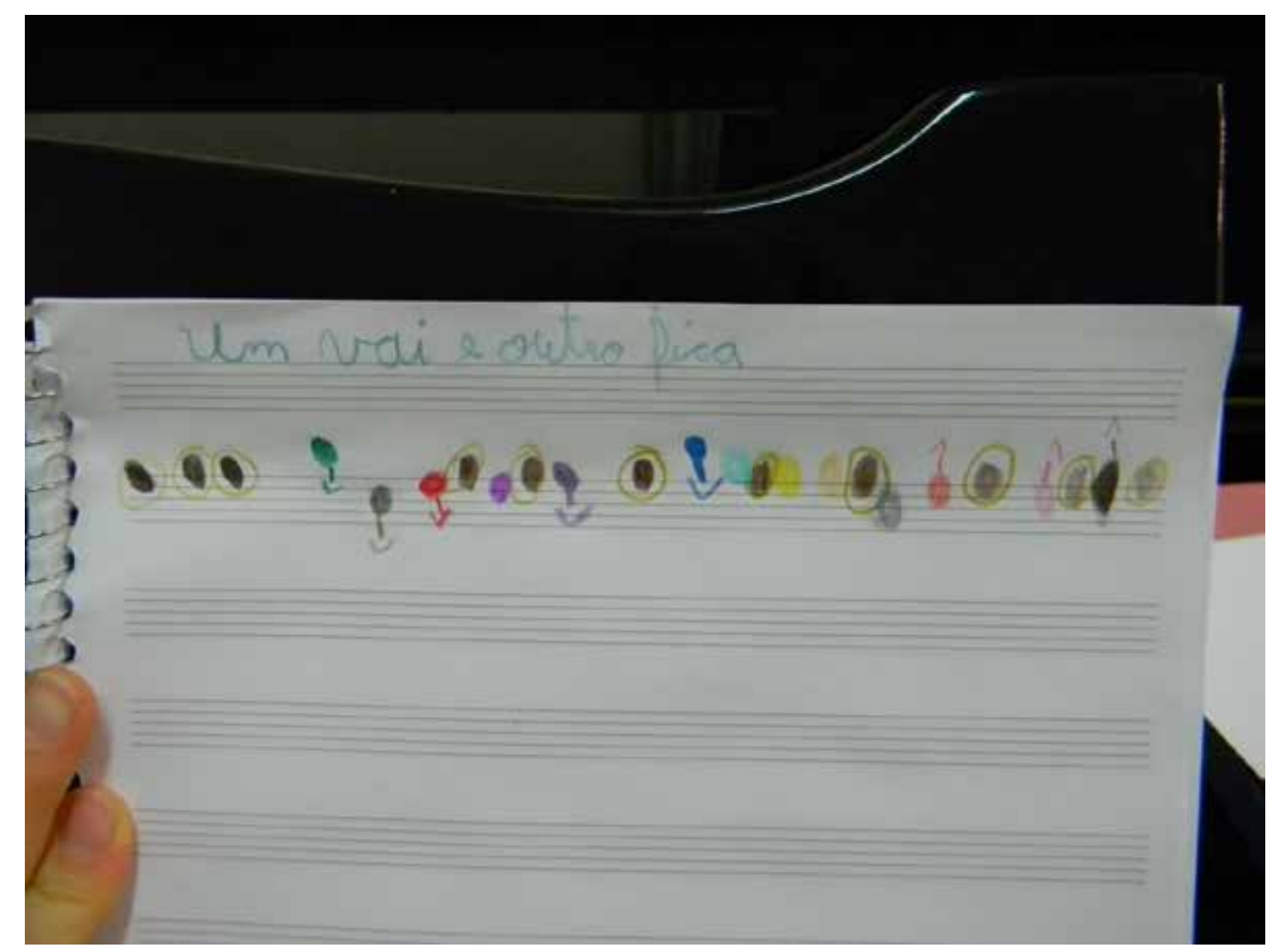

Fig. 1 - Larissa (7 anos). Fonte: Arquivo da autora, 2012.

No registro feito por Larissa, as notas que estão circuladas são tocadas pelo dedo indicador (dedo 2) da mão esquerda, que permanece na mesma nota, enquanto as setas viradas para baixo indicam que o dedo indicador da outra mão toca no registro grave e, 
por sua vez, as setas apontadas para cima informam que ele deve tocar agora na região aguda do piano.

Quando percebo que um tema é persistente, entramos então no que chamei aqui de "quebra-cabeça" sonoro: as possibilidades de trabalhar com ideias musicais, transformando-as em composições. Uma primeira opção que ofereço às crianças é a de repetir o tema. Mas a ideia da repetição é grávida de outras tantas: repetir mudando a intensidade, repetir uma oitava acima, repetir mudando o acompanhamento, mudando o andamento, acrescentando uma introdução ou uma coda, e outras tantas possibilidades que as crianças mesmas descobrem e que julgam interessantes para fazerem suas músicas se tornarem mais desenvolvidas. Assim é que, como num quebra-cabeça em que as peças vão se acoplando umas às outras para dar lugar a uma imagem, os temas das crianças vão sendo repetidos, acrescidos, modificados, e se constituem em pequenas composições.

Muitas vezes as músicas de outros compositores que estão tocando suscitam possibilidades de também criar as suas a partir de algum aspecto: pentacordes, escalas, acompanhamentos em quintas, modos maior e menor, acordes. E assim temos mais material para nosso jogo de quebra-cabeça musical. Camila (onze anos), nesse processo de inventar suas próprias músicas, chegou à aula numa segunda-feira de manhã com a sua composição com acompanhamento da mão esquerda escrita. Ela usou elementos que "pegou" da peça que estava tocando e me disse: "Uso as coisas que aprendo na aula". O que fiz a seguir foi sugerir que ela escolhesse como queria tocar sua "mini música 3". Depois de experimentarmos na aula as possibilidades que lhe apresentei, escrevi ao lado da partitura as opções para ela tocar em casa e escolher a versão que mais gostasse para tocar na repetição da sua música. A fotografia da sua música foi tirada no dia em que ela chegou na aula com essa escolha já feita.

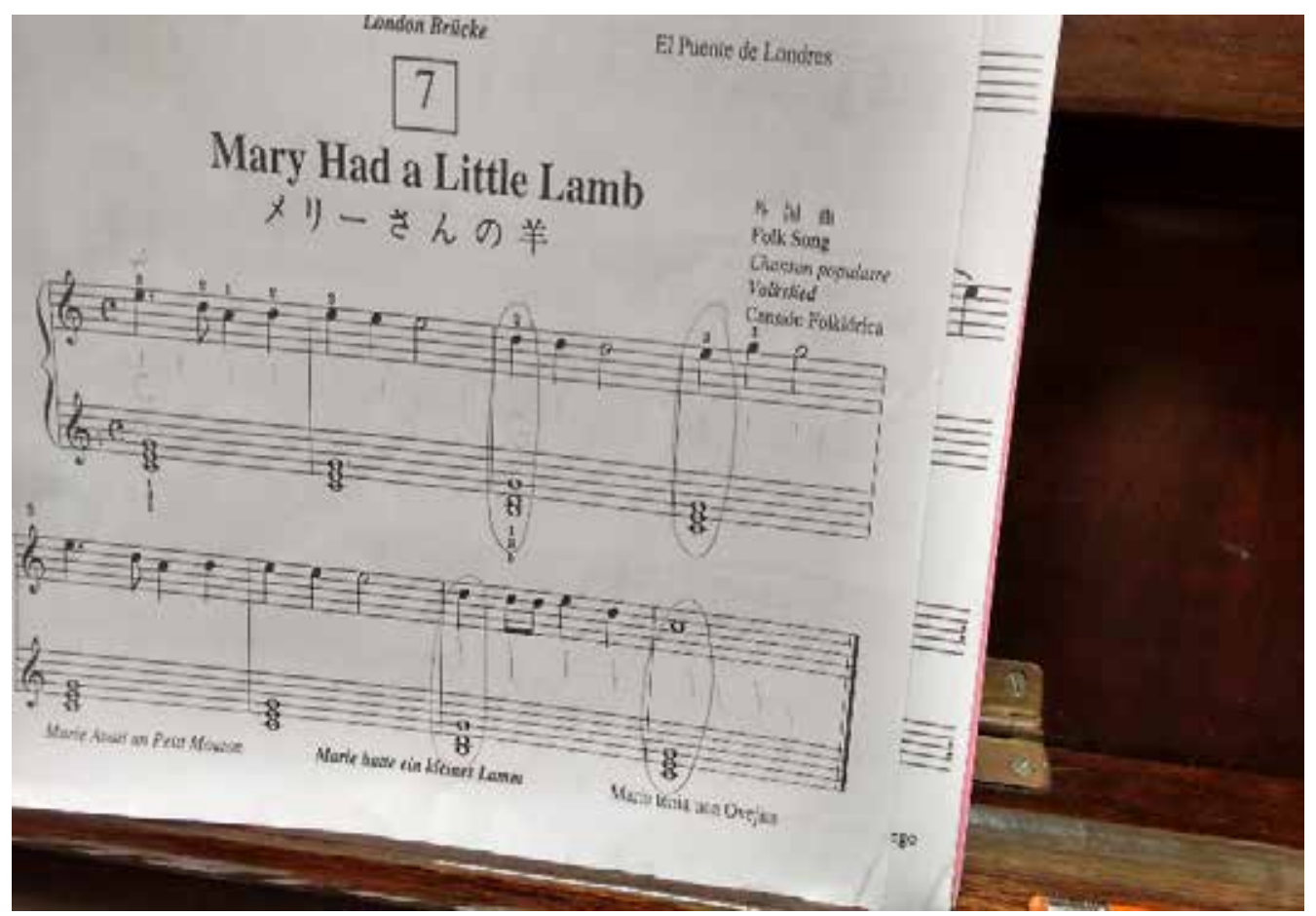

Fig. 2 - Camila, peça do seu repertório. Fonte: Arquivo da autora, 2017. 


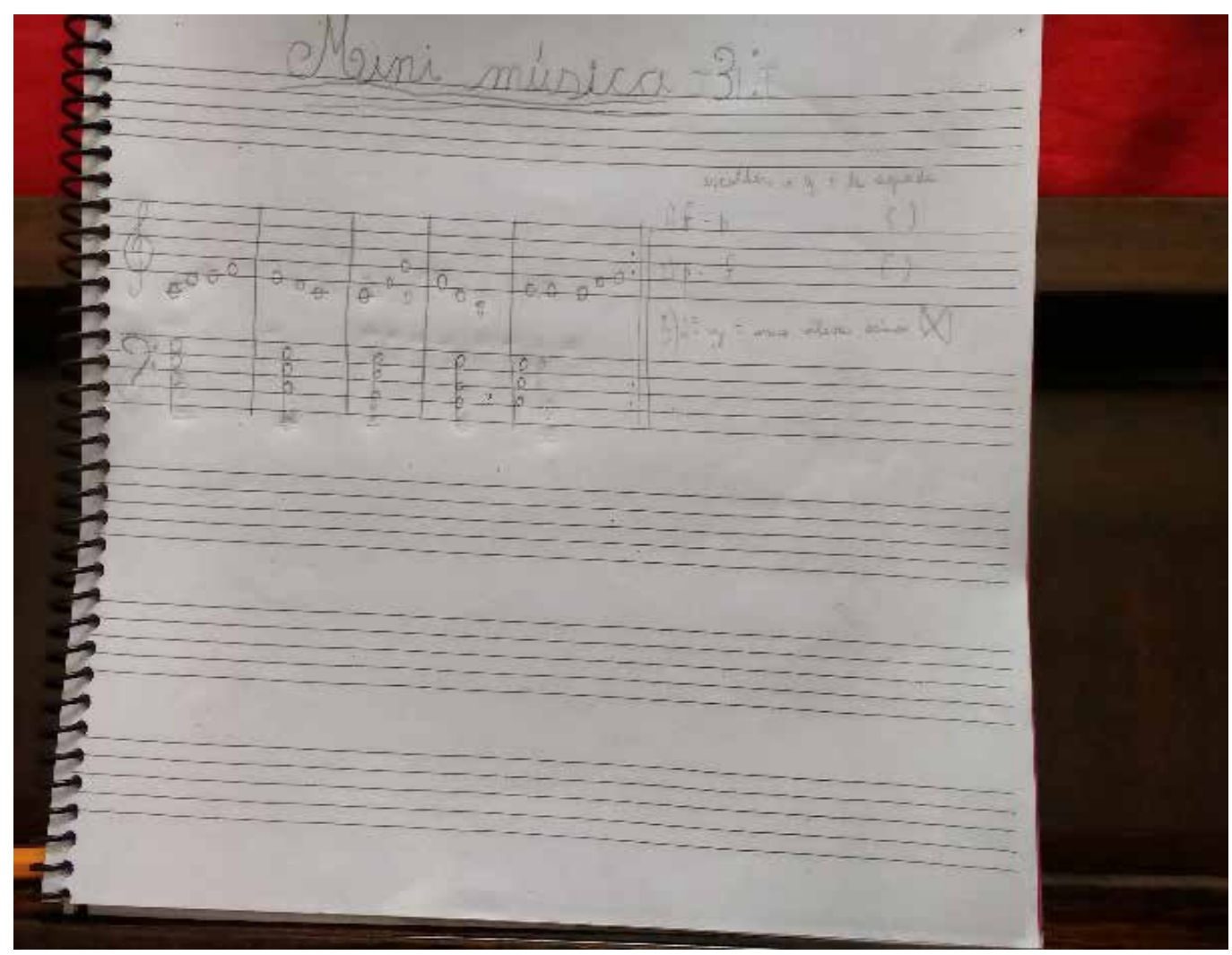

Fig. 3 - Composição de Camila, a partir da peça anterior. Fonte: Arquivo da autora, 2017.

Tudo parece mesmo um jogo no qual as crianças mergulham e, nesse caminho de investigação e criação no piano, vou chamando a atenção para a escuta e para os pequenos detalhes que tornam as músicas mais expressivas, como crescendos e decrescendos, fraseados, rallentandos, articulações, contrastes entre intensidades, andamentos e formas, elementos constitutivos da linguagem que pouco a pouco vão compondo a aprendizagem musical aplicada ao estudo do instrumento.

A escrita, tradicional ou inventada pelas crianças para registrar suas composições, vai sendo desenvolvida tanto na leitura e interpretação das peças de outros compositores que compõem o repertório de cada criança como nos registros que elas mesmas fazem das suas músicas. Samara (12 anos) me disse que gosta de inventar músicas aleatoriamente, mas que não gosta de escrever suas músicas, ainda que, segundo ela, "mesmo que eu me esqueça". Abaixo, a música de Samara em processo de registro, pois as crianças também vão aperfeiçoando a escrita, tornando-a mais precisa. Como exemplo, disse a Samara que a figura da mínima já informa que a duração é longa, e que não é preciso escrever os traços que seguem essas figuras todas as vezes em que aparecem no seu registro musical. 


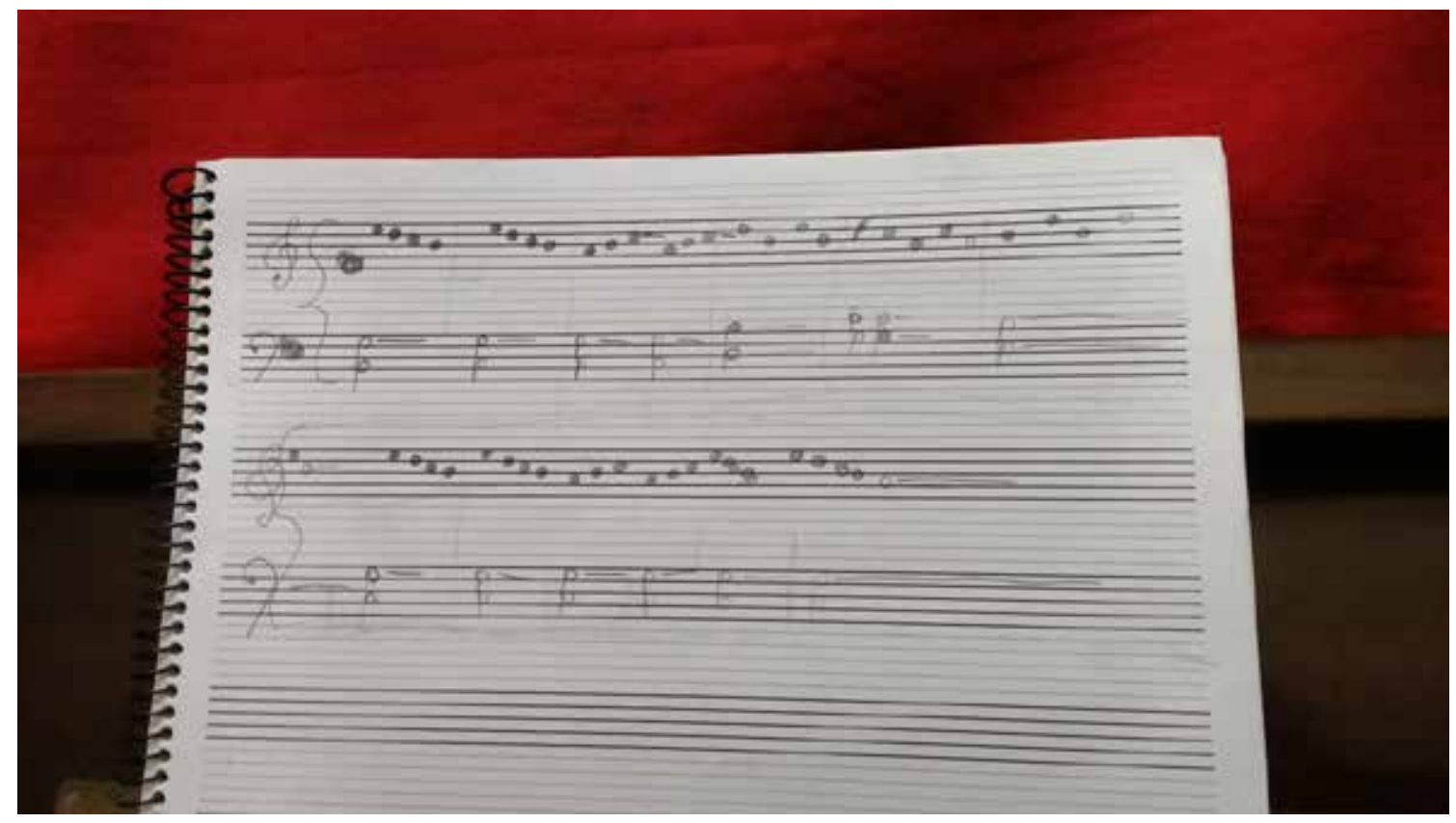

Fig. 4 - Samara (11 anos). Fonte: Arquivo da autora, 2017.

As músicas das crianças ganham nomes inusitados: "Misteriosa", "Forbilix music", "Bianca na Arábia", "Um dia louco de Gabi", "Fofoquinhas", "Pedras de cristal". Algumas vezes as crianças não têm nomes para suas composições ou ficam em dúvida, e estas assumem nomes temporários que podem até mesmo ficar como "Música nำ1" ou "Música sem nome".

Nomear as músicas é um momento revelador do mundo de vida das crianças, do que as afeta, do seu imaginário que é tão ricamente alimentado na EMIA. Os nomes das suas músicas falam de sentimentos, valores, experiências, dos seus bichos de estimação e de situações que aconteceram com elas; são situações vividas ou imaginadas pelas crianças, que se expressam por meio dos sons do instrumento. Um improviso de Thiago (oito anos) ganhou o nome de "Só não me chame de fofoqueiro" porque, segundo ele me disse, sua música "fala de segredos e de coisas que se pode contar".

Algumas crianças inventam séries como a de Camila, com suas músicas números 1 , 2 e 3 e 4, já caminhando para a música de número 5. São músicas curtas, com temas repetidos ou desenvolvidos que constituem um conjunto e contam histórias, momentos, sensações e sonhos. Mas todas elas, por meio dos sons do piano que são inicialmente experimentados e depois organizados, expressam as ideias e as vozes das crianças.

Esse é um trabalho que venho fazendo na escola e que, de 2009 a 2012, realizei em parceria com uma professora de flauta doce, Claudia Freixedas (CUNHA; FREIXEDAS, 2011, 2014). Um dos marcos desse nosso trabalho pensado e desenvolvido em conjunto foi a série de audições chamada por nós de "Compositores e Intérpretes", na qual as crianças apresentavam em uma das partes da audição as suas composições e, na outra parte, tocavam as músicas dos compositores que estavam estudando. As composições das crianças, no piano e na flauta doce, eram, desse modo, colocadas no mesmo programa, indicando que as músicas compostas por elas eram igualmente importantes 
para serem tocadas e conhecidas pelas outras crianças e por suas famílias.

Segundo Freixedas (2015), ao refletir sobre esse trabalho:

Observamos, ao longo desses quatro anos do projeto, que durante estas audições, os alunos evidenciavam uma atitude positiva, confirmada pela participação e o envolvimento em todas as audições, tanto como intérpretes de suas próprias composições, como intérpretes de outros compositores.

Em um momento de reflexão, realizado com duas alunas de onze anos, logo após uma das audições "Compositores e Intérpretes", questionei-as sobre as diferenças entre tocar peças compostas por elas e obras de outros compositores. Ambas disseram que era interessante tocar músicas de outros compositores, mas que também era "bacana" tocar músicas compostas por elas mesmas. (FREIXEDAS, 2015, p. 111).

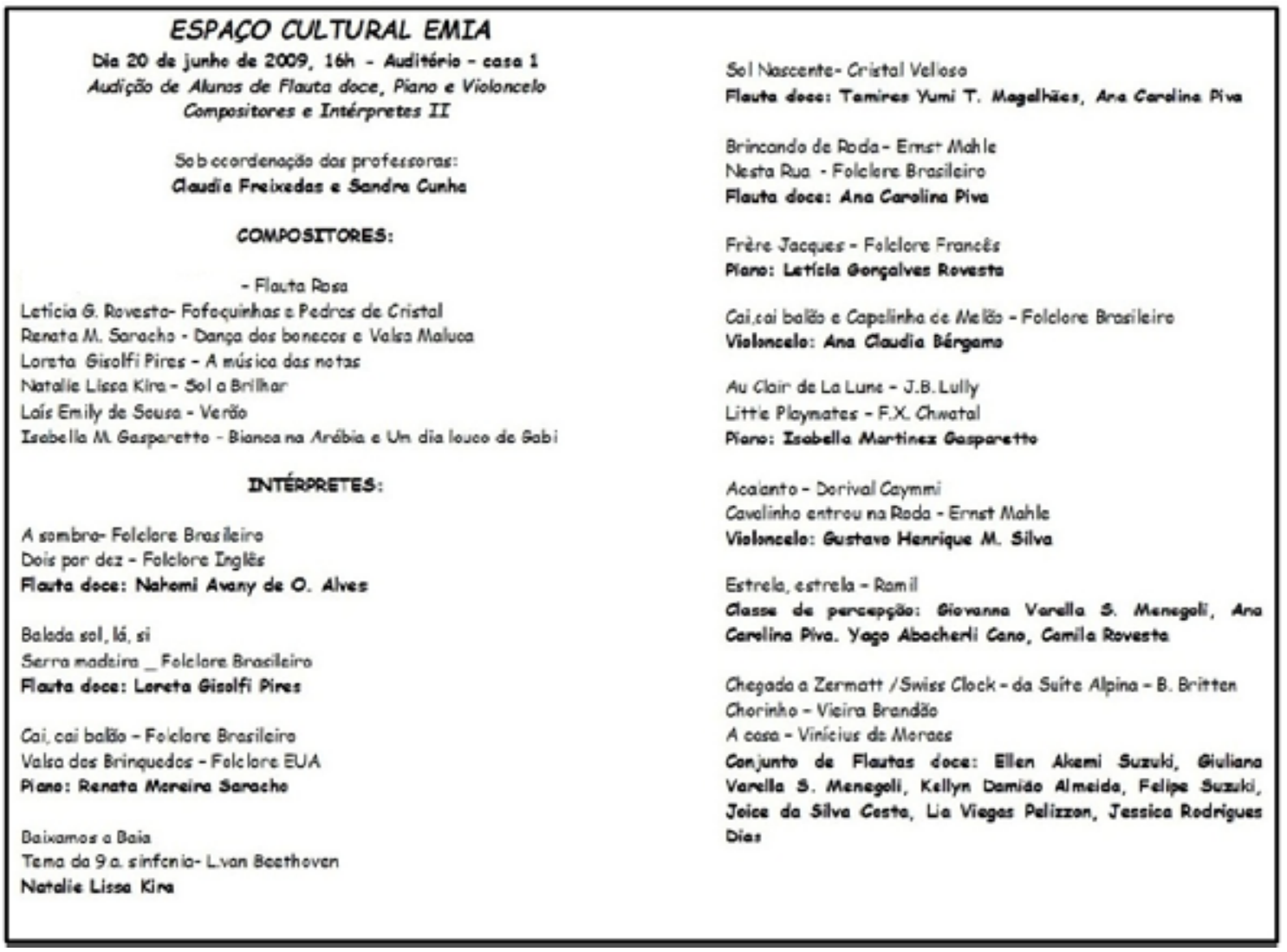

Fig. 5 - Programa da audição "Compositores e Intérpretes II", realizada em 2009. Fonte: Freixedas, 2015.

Quando afirmo que as crianças fazem música, estou considerando-as competentes para atuarem e se expressarem a partir daquilo que vivem e sabem, sem compará-las com as composições adultas e profissionais, mas com o intuito de olhar para elas e ouvir o que criam tentando apreender os sentidos que elas atribuem ao que fazem. Encontro apoio em Brito (2007), que primeiramente questiona e em seguida afirma: 
Seria mais música uma melodia simples, de três ou cinco notas que uma criança repete no piano que recém começou a "estudar", ou as improvisações livres que ela realiza quando pode "demarcar seu território" com liberdade? O que define a música é o sistema que the organiza ou as forças sonoras que emanam de gestos, fundando tempos e espaços? Seria música apenas aquela que se orienta pela ordenação das notas musicais ou também aquela que prima pela produção de sonoridades? Música das notas ou das sonoridades? (BRITO, 2007, p. 82-83).

Se as crianças têm a possibilidade de experienciar, de fazer/refletir, de explorar, de pesquisar, de criar e também sistematizar conhecimentos, emergem continuamente descobertas e reflexões que nos informam sobre os modos de ser e estar das crianças; são pistas que nos permitem melhor conhecê-las, bem como fazer música com elas compartilhando seus processos de auto-organização e de transformação de experiências. (BRITO, 2007, p. 94).

É claro para mim que as músicas inventadas pelas crianças não surgem como mágica ou são fruto da controversa noção de "talento". O que as crianças inventam são interpretações realizadas a partir do caldo cultural e musical em que vivem, na EMIA e fora dela, e expressam, em última instância, o que elas têm a dizer também no que se refere ao seu conhecimento artístico pela via da música.

A música das crianças seria, então, o resultado do que elas absorvem do mundo musical adulto no qual estão inseridas, do que estão ouvindo desde antes do seu nascimento, de uma musicalidade assim constituída e também daquilo que escolhem para dar sentido às suas interpretações desses fatos sonoros. As músicas inventadas pelas crianças com as quais trabalhei revelam ser resultantes da apropriação e da interpretação que elas fazem do caldo cultural e musical adulto em que estão mergulhadas e para o qual contribuem com a criação de formas musicais perceptíveis e profundamente expressivas. (CUNHA, 2014b, p. 76).

\section{Notas finais}

Abordar o tema da participação das crianças na sua formação artística e na iniciação ao estudo do piano na EMIA significa buscar a compreensão de como elas constroem seu conhecimento na relação estreita que estabelecem com seus professores. Pensar a participação infantil nesse contexto educativo é pensar nos tempos e espaços preenchidos com suas ideias, iniciativas, recusas, falas, silêncios, que reforçam e ampliam o que foi planejado e preparado pelos professores.

As negociações entre a autora e as crianças nas aulas de piano determinam as continuidades dos processos e as transformações no desenvolvimento dos trabalhos, e, pela via do afeto, fortemente presente nos encontros, modifica o humano, possibilitando momentos únicos vividos em busca do fazer artístico que lhes confere sentidos.

A participação das crianças nos processos de ensino e aprendizagem da linguagem musical e dos instrumentos marca as interações entre professores e crianças e está, portanto, diretamente relacionada às práticas pedagógicas. Quanto mais fechadas, guiadas por procedimentos e metodologias estabelecidas de antemão, com propostas 
determinadas pelos adultos, menores são as possibilidades das crianças participarem e dos adultos atuarem como parceiros nesses percursos educativos. Quanto mais abertas e essencialmente guiadas pelas investigações de ambos os atores - crianças e seus professores - e quando têm como resultado a criação artística, maior é a chance das crianças tomarem de fato parte nos processos, o que torna os professores menos adultocentrados e, consequentemente, mais éticos na sua relação com as crianças.

$\mathrm{Na}$ aprendizagem do piano, abrir espaço na agenda do ensino desse instrumento para as invenções das crianças, seja improvisando livremente ou de modo direcionado e orientado por seus professores, nas composições que elas criam, as crianças se sentem acolhidas, estimuladas e valorizadas na sua ação artística.

$\mathrm{Na}$ EMIA, a participação das crianças tem como resultante o que pode ser visto e ouvido a cada porta e janela que se abre na escola e que continua nos espaços do parque e avança pela cidade nos espaços culturais nos quais elas se apresentam a cada ano. São acontecimentos e objetos artísticos, efêmeros ou duradouros, que me permitem afirmar que nessa escola as crianças participam criando e fazendo arte, a arte das crianças. Essa arte emerge do entrelaçamento de experiências, saberes, ideias, desejos, interesses e sonhos compartilhados entre adultos e crianças e entre crianças e crianças.

Reconhecer as crianças como produtoras de arte e como partícipes desses processos de construção de conhecimento contribui para o reconhecimento da escola como um espaço de aprendizagem artística que é respeitador das crianças, como um espaço de resistência da infância inventiva, viva e brincante. A EMIA é, também, escola de formação de crianças cidadãs.

Nesse texto, ao refletir sobre a participação das crianças na aprendizagem do piano na EMIA, mais do que sobre o ensino e as conquistas e habilidades para tocá-lo, busquei fazê-lo a partir de um referencial que busca aproximações com elas, pensando que essa participação é fundamental para que se enxerguem como parte integrante nesses processos de aquisição de conhecimento.

O que essas aproximações revelam são os significados que as crianças atribuem ao que me proponho a construir na parceria com elas, e é por isso que trabalhos dessa natureza, com crianças, se fazem necessários e até mesmo urgentes para a iniciação delas no estudo do piano. De outro modo, continuaremos a tratar a iniciação das crianças no instrumento de um modo distante delas e dos seus pontos de vista, modo esse adultocentrado que, por isso mesmo, não consegue capturar o interesse e o envolvimento delas nas aulas e cursos.

O que as abordagens criativas na aprendizagem do instrumento e o trabalhar em profunda sintonia com as crianças e seus modos de ser indicam é a necessidade de relações menos assimétricas entre adultos e crianças, que devem se pautar pelo mesmo interesse: tocar piano e se encantar com o resultado sonoro produzido.

Finalizo com o depoimento de um aluno de teatro de uma turma de crianças entre sete e 13 anos de idade, publicado no livro EMIA, Escola de Arte, Casa de Crianças: uma experiência de 35 anos (ANDRÉ, 2016, p. 81):

"Para mim, a EMIA é inspiração, é uma caixinha de criatividade, e a chave é o aluno. Encaixar a chave na fechadura é papel dos professores". (Theo). 


\section{Referências}

ANDRE, Paulo Farah. Pontos de Vista, uma entrevista. In: FRAGA, Andréa (Coord.). EMIA, escola de artes, casa de crianças: uma experiência de 35 anos. São Paulo: SMC, 2016.

ARNSTEIN, Serry R. A Ladder of Citizen Participation. In: Journal of the American Planning Association, Vol. 35, n. 4, p. 216-224, 1969.

BARBOSA, Maria Carmem Silveira; COLL DELGADO, Ana Cristina; TOMÁS, Catarina Almeida. Estudos da infância, estudos da criança: quais campos? Quais teorias? Quais questões? Quais métodos? In: Inter-Ação, Goiânia, v. 41, n. 1, p. 103-122, jan./abr. 2016. Disponível em: <http://dx.doi.org/10.5216/ia.v40i3.35869>.

BRITO, Maria Teresa Alencar de. Por uma Educação Musical do Pensamento: novas estratégias de comunicação. 288 f. 2007. Tese. (Doutorado em Comunicação e Semiótica) - PUC-SP, São Paulo, 2007.

BRITO, Teca Alencar de. Koellreutter Educador: o humano como objetivo da educação musical. São Paulo: Peirópolis, 2001.

CUNHA, Sandra. EMIA: escola de arte, casa de crianças. In: FRAGA, Andréa (Coord.). EMIA, escola de artes, casa de crianças: uma experiência de 35 anos. São Paulo: SMC, 2016.

CUNHA, Sandra et al. (Orgs.). O que as "Narrativas Poéticas" têm a nos dizer sobre o ensino de Arte para crianças na EMIA? In: EMIA em Revista. Edição CORPOCASA. São Paulo: SMC/Divisão de Formação Artística e Cultural/EMIA, 2014a.

CUNHA, Sandra Mara da. Eu Canto Pra Você: saberes musicais de professores da pequena infância. 186 f. 2014. Tese. (Doutorado em Educação) Universidade de São Paulo. São Paulo, 2014b.

CUNHA, Sandra Mara da; FREIXEDAS, Cláudia Maradei. Explorers of Sounds: the music of the children. 31st. ISME World Conference on Music Education. 15-20 July. Porto Alegre - Brazil, 2014. Disponível em: <https://www.academia.edu/8599415/Explorers_ of_Sounds_the_music_of_the_children>.

CUNHA, Sandra Mara da; FREIXEDAS, Cláudia Maradei. Compositores e Intérpretes: a criação na aula de instrumento. Foro Latino Americano de Educação Musical - FLADEM. Guatemala, 2011. Disponível em: <https://www.academia.edu/7153729/FLADEM_2011_Mostra_de_Musicaliza\%C3\%A7\%C3\%A3o_Compositores_e_Int\%C3\%A9rpretes_a_cria\%C3\%A7\%C3\%A3o_na_aula_de_instrumento_1>. 
CUSSIÁNOVICH, Alejandro Villarán. Protagonismo, participación y ciudadanía como componente de la educación y ejercicio de los derechos de la infancia. In: Historia del pensamiento social sobre la infancia. Lima: Universidad Nacional Mayor de San Marcos. Fondo Editorial de la Facultad de Ciencias Sociales: 2002. p. 86-102.

FREIXEDAS, Claudia Maradei. Caminhos Criativos no Ensino da Flauta Doce. 151 f. 2015. Dissertação (Mestrado em Música) - Universidade de São Paulo, São Paulo, 2015.

FONTERRADA, Marisa Trench de Oliveira. Ciranda de Sons: práticas criativas em educação musical. São Paulo: UNESP, 2015.

GAINZA, Violeta Hemsy de. Palitos Chinos (shop-sticks): para la iniciación al piano. Buenos Aires: Barry, 1987.

GONÇALVES, Maria de Lourdes Junqueira. Educação Musical através do Teclado: etapa de musicalização. Manual do professor, vol. 1. Rio de Janeiro: [s. n.], 1986.

HART, Roger. Children's Participation: from Tokenism to citizenship. Florence, Italy: UNICEF International Child Development Centre, 1992.

LANSDOWN, Gerison. The Realisation of Children's Participations Rights: critical reflections. In: PERCY-SMITH, Barry; THOMAS, Nigel. A Handbook of Children and Young People's Participation: perspectives form theory and practices. USA/Canada: Routledge, 2010.

LINO, Dulcimarta Lemos; RICHTER, Sandra Regina Simonis. Rodas Poéticas e Libretos de Criação: experiências lúdicas de habitar a linguagem na educação infantil. In: XI Anped Sul. Curitiba: UFPR, 24-27 Jul./2016. Disponível em: <http://www.anpedsul2016.ufpr. br/wp-content/uploads/2015/11/Eixo-5_DULCIMARTA-LEMOS-LINO-SANDRA-REGINA-SIMONIS-RICHTER.pdf>.

MONTANDON, Maria Isabel. Aula de Piano e Ensino de Música - análise da proposta de reavaliação da aula de piano e sua relação com as concepções pedagógicas de Pace, Verhaalen e Gonçalves. 1992. Dissertação (Mestrado em Música) - UFRGS, Porto Alegre, 1992.

OLSSON, Liselott Mariett. Taking Children's Questions Seriously: the need for creative thought. Global Studies of Childhood, Vol. 3, n. 3, p. 230-253, 2013.

. Eventicizing Curriculum: learning to read and write through becoming a citizen of the world. Journal of Curriculum Theorizing, Vol. 28, n.1, p. 88-107, 2012.

ROCHA, Ana Cristina Rossetto. Memórias de Iniciação Artística e a Criação de Si. 243 f. 
2017. Tese (Doutorado em Educação) - Universidade de Campinas, Campinas, 2017.

SARMENTO, Manuel Jacinto. Estudos da Infância e Sociedade Contemporânea: desafios conceptuais. O Social em Questão. Revista do Departamento de Serviço Social, Rio de Janeiro,PUC-Rio, Ano 12, n. 21-1, p. 15-30, 2009.

. Visibilidade Social e Estudo da Infância. In: VASCONCELLOS, Vera Maria Ramos; SARMENTO, Manuel Jacinto (Org.). Infância (in) visível. Araraquara: Junqueira \& Marin, 2007. p. 25-49.

Imaginários e Culturas da Infância. CEDIC - Centro de Documentação e Informação Sobre a Criança. Centro de Estudos da Criança, Universidade do Minho, 2003. Disponível em: http://cedic.iec.uminho.pt/Textos_de_Trabalho/textos/ImaCultInfancia.pdf>. Acesso em 16 set. 2017.

SCHAFER, Murray. O Ouvido Pensante. São Paulo: UNESP, 1991.

THOMAS, Nigel. Towards a Theory of Children's Participation. International Journal of Children's Rights, Leiden/Boston, Vol. 15, p. 199-218, 2007. 